\title{
EDITORIAL
}

\section{Admissão do Jornal de Pneumologia na SciELO Brasil: uma vitória com novos desafios}

A Scientific Eletronic Library Online - SciElO é uma biblioteca virtual que abrange uma coleção selecionada de periódicos científicos brasileiros. É um projeto da Fapesp (Fundação de Amparo à Pesquisa do Estado de São Paulo) em parceria com a Bireme (Centro Latino-Americano e do Caribe de Informação em Ciências da Saúde) que tem por objetivo o desenvolvimento de uma metodologia comum para a preparação, armazenamento, disseminação e avaliação científica em formato eletrônico ${ }^{(1)}$. A curto prazo, o projeto busca aumentar radicalmente a visibilidade, a acessibilidade $e$ a credibilidade nacional $e$ internacional da publicação científica da América Latina e do Caribe. A longo prazo, busca contribuir para o aumento do impacto da produção científica nacional ${ }^{(1)}$.

A aplicação pioneira é o site SciELO Brasil ${ }^{(2)}$, mas o Chile já está implementando a segunda aplicação(3) e outros países estão avaliando ou recebendo treinamento da Metodologia SciELO. Em 1999, foi inaugurada uma biblioteca temática regional que cobre a área de saúde pública com periódicos científicos da América Latina e Espanha ${ }^{(4)}$.

A coleção SciElo Brasil inclui periódicos científicos que publicam predominantemente artigos resultantes de pesquisa científica original e outras contribuições científicas significativas para a área específica do periódico. Há a exigência de um número mínimo de artigos por ano $e$ a originalidade e a qualidade destes artigos são verificadas pelo Comitê Consultivo da SciELO. Além disso, o periódico deve ter um conselho editorial composto por especialistas reconhecidos cujos nomes devem ser de conhecimento público, ter os processos de revisão e de aprovação das contribuições feitos por pares, manter a periodicidade e a pontualidade e os artigos devem conter título, resumo e palavras-chave no idioma do texto $e$ no idioma inglês, quando este não é o idioma do texto. As contribuições podem estar escritas nos idiomas português, inglês ou espanhol(2).

Todos os indicadores adotados para a admissão de periódicos na SciELO Brasil aplicam-se também para a sua permanência. Entretanto, há outros indicadores específicos do desempenho dos periódicos na coleção SciELO, que devem ser utilizados para justificar a sua permanência na coleção: pontualidade de envio dos arquivos, indicador de uso do periódico (medido pela evolução mensal do número de acessos ou visitas ao conteúdo do periódi- co) e Indicador de impacto (medido com base nas citações que o periódico recebeu) ${ }^{(2)}$.

As informações acima mostram a importância que a admissão do Jornal de Pneumologia na SciELO Brasil tem para todos os sócios da Sociedade Brasileira de Pneumologia e Tisiologia. Nossa revista, que já estava indexada no Index Medicus Latino Americano (IMLA) e Periódica (Índice de Revistas Latinoamericanas en Ciencias), passou por uma avaliação rigorosa e criteriosa realizada pelos membros do Comitê Consultivo SciELO Brasil e ingressou no seleto grupo de periódicos científicos nacionais desta coleção.

Vencida esta primeira etapa - fruto do trabalho de quase 30 anos de todos os envolvidos com a publicação do Jornal de Pneumologia - temos o desafio de manter a revista na SciELO Brasil. Para isto, vamos continuar a política adotada pelo atual Conselho Editorial de publicar, após rigorosa revisão, preferencialmente contribuições originais e de respeitar religiosamente a periodicidade e a pontualidade da revista.

Entretanto, há também dois novos indicadores (uso do periódico e impacto) com os quais precisamos nos preocupar.

Para obtermos um indicador de uso do periódico elevado temos que estudar a possibilidade de colocar os textos do Jornal de Pneumologia em inglês - que é o idioma universal da Ciência - permitindo assim que pesquisadores de todo o mundo compreendam o material publicado por nós. Estaríamos, portanto, ampliando a área de penetração do Jornal de Pneumologia. Para não descaracterizar totalmente a revista, poderíamos utilizar o português na versão impressa $e$ o inglês $e$ o português na versão online.

Já sobre o indicador de impacto, grande parte da tarefa depende dos autores, isto é, depende de nós mesmos. Temos que aprender a citar os trabalhos brasileiros para valorizar nossa produção científica. Nós não nos citamos! Assim, mantemos os periódicos brasileiros com baixos índices de impacto e não quebramos este círculo vicioso. Como exemplo, aponto o pequeno número de citações de artigos do Jornal de Pneumologia nas referências dos trabalhos publicados no próprio Jornal de Pneumologia.

Além do empenho de cada um de nós, utilizando em nossos trabalhos referências pertinentes de artigos publi- 
cados no Jornal de Pneumologia, a admissão na SciELO Brasil, que sem dúvida dará mais divulgação à nossa revista, e sobretudo uma versão online em inglês poderão contribuir muito para aumentar o impacto do Jornal de Pneumologia.

Enfim, estes são os desafios advindos da vitória. Tenho certeza que os membros do Conselho Editorial, grandes responsáveis pelo êxito do Jornal de Pneumologia, que

\section{REFERÊNCIAS}

1. SciELO. Scientific Eletronic Library Online. Disponível em: http:// www.scielo.org

2. SciELO Brasil. Scientific Eletronic Library Online. Disponível em: http:/ /www.scielo.br a Diretoria da SBPT, com seu apoio incondicional às necessidades do Jornal de Pneumologia, e que a Priscilla, secretária dedicada e entusiasta, aceitarão os desafios.

Obviamente, não haveria vitória se não houvesse autores. Espero que eles também aceitem os desafios.

Prof. DRA. Thais Helena Abrahão ThOMAZ QueluZ Editora

3. SciELO Chile. Scientific Eletronic Library Online. Disponível em: http:/ /www.scielo.cl

4. SciELO Saúde Pública. Scientific Eletronic Library Online. Disponível em: http://www.scielosp.org 